\title{
Influence of Pulsation Deformations on Properties of Steel Grade Cr18Ni10
}

\author{
Tibor Kvackaj ${ }^{1, *}$, Lucia Sokolová', Martin Vlado', Vladimír Vrchovinsky ${ }^{1}$, Rudolf Misicko', Zbysek Novy ${ }^{2}$ \\ ${ }^{1}$ Technical University in Kosice, Faculty of Metallurgy, Letná 9, 04001 Kosice, Slovakia \\ ${ }^{2}$ Comtes FHT, Plzeñ, Czech Republic
}

(Received December 11, 2003; final form January 20, 2004)

\begin{abstract}
This paper presents initial results of pulsatory forming performed on a pulsator at the Department of Metal Forming, Faculty of Metallurgy, Technical University in Kosice. Pulsatory forming (stress-cycling) is a non-conventional forging method based on application of a variable pulsation frequency during the metal forming process. The pulsation frequency and amplitudes during pulsatory forming are new technological parameters using which we can influence both processes taking place in the formed metal (recrystallization, grain growth, transformation processes) and the contact area between the formed metal and the forming tool (the character of friction and related impacts on the deformation course and the formability). The influence of summary deformation as a function of pulsation frequency and the influence of the geometrical parameter " $\Theta$ " on the microstructure (AGS diameter), mechanical properties $R_{p 0,2} ; R_{m}: A_{5}, Z$ and geometry of experimental samples of steel grade Crl8Nil0 were analyzed. At a value of summary deformation of $25 \%$ (at the pulsation frequency of 30 $\mathrm{Hz}$ ) a very good compromise was achieved between yield strength, tensile strength - elongation and contraction. The maximum value of $R_{p 0,2}$ and $R_{m}$ was achieved at the geometrical parameter $\Theta=20 \%$. At a value of parameter $\Theta=20 \%$ a high value was achieved
\end{abstract}

of plastic properties $A_{5}$ and $Z$ (ca $80 \%$ ). The value of geometrical parameter $\Theta$ of $20 \%$ or the highest value of $\Theta$ improved the flow of material at pulsation forming process point of view of the lower of plastic deformation heterogeneity.

Key words: pulsator, pulsation forming, summary deformation, pulsation frequency, microstructure, mechanical properties, geometrical parameter i - barrel ratio of the samples

\section{INTRODUCTION}

The pulsation frequency and amplitudes during pulsatory forming are new technological parameters using which we can influence both important processes taking place in the formed metal (recrystallization, grain growth, transformation processes) and the contact area between the formed metal and the forming tool (the character of friction and related impacts on the deformation course and the formability).

Controlling the force values during pulsatory forming (decreases and re-increases) can promote and speed up the course of dynamic recrystallization $11 \%$. The grain size - the most important structural factor can also be activated by pulsatory forming, resulting in finer-grained microstructures, while the recrystallization

'Corresponding author: T. Kvackaj, Tel: ++421-55-6024198, E-mail: tibor.kvackaj@tuke.sk 
kinetics (its higher intensity) and the grain refinement have a positive effect on the material plasticity and formability $/ 1,2 /$. The cyclic decrease and increase of stress on the contact areas between the formed metal and the forming tool improve the conditions for elementary slips, which must take place in material flowing in the desired direction $/ 3 /$.

The paper presents results of research made on an installed pulsator, whose scheme is shown in Fig. 1. The influence of summary deformation as a function of pulsation frequency on microstructure (austenite grain size - AGS diameter) and mechanical characteristics $R_{p 02} ; R_{m} ; A_{5} ; Z$, was analyzed. The dependence between geometrical parameter " $\Theta$ " and mechanical characteristics was also investigated.

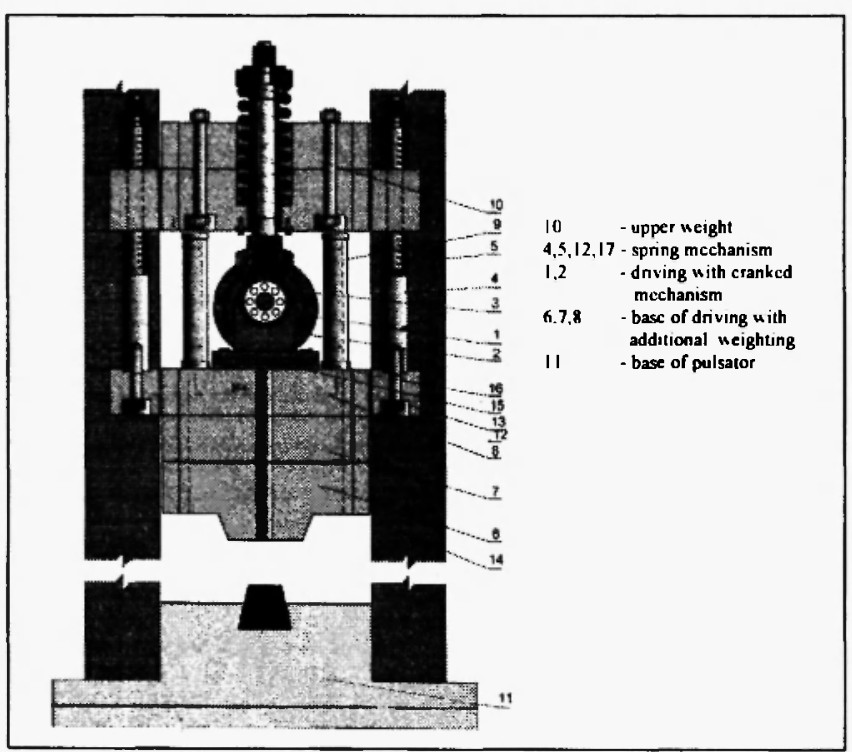

Fig. I: Pulsator

\section{MATERIAL AND EXPERIMENTAL METHODS}

For experiments made on the pulsator, cylindrical specimens were used with the dimensions $h_{0}=30 \mathrm{~mm}$ and $d_{0}=20 \mathrm{~mm}$. The chemical composition of the experimental material is shown in Table 1 . The experimental program, including the heating temperatures and the deformation temperatures, together with the selected pulsation frequency, is shown in Table 2. Pulsatory forming was made at deformation temperatures that represented finishing temperatures, while the as-forged structure was fixed by water quenching. After forming and quenching the specimens, $R_{\mathrm{p} 0,2} ; R_{\mathrm{m}} ; A_{5} ; Z$, and geometrical parameter $\Theta\left(\mathrm{V}_{\text {Barrel }} /\right.$ $\left.V_{0}\right) \times 100[\%]$ were evaluated. The results are supported by metallographic analysis using optical light microscopy, where the character of microstructure and the grain size was evaluated.

Table 1

Chemical composition of steel grade $\mathrm{Cr} 18 \mathrm{Ni} 10$ [weight \%]

\begin{tabular}{|c|c|c|c|c|c|c|c|c|}
\hline Steel & $\mathbf{C}$ & $\mathbf{M n}$ & $\mathrm{Si}$ & $\mathbf{C r}$ & $\mathbf{N i}$ & $\mathbf{T i}$ & $\mathbf{P}$ & $\mathrm{S}$ \\
\hline Cr18Ni10 & 0,03 & 1,2 & 0,5 & 18,6 & 10,8 & 0,26 & 0,008 & 0,023 \\
\hline
\end{tabular}

Table 2

Experimental procedure

\begin{tabular}{|c|c|c|c|}
\hline $\begin{array}{c}\text { Heating } \\
\text { temperature } \\
{[\mathbf{K}]} \\
\end{array}$ & $\begin{array}{c}\text { Deformation } \\
\text { temperature } \\
{[\mathrm{K}]}\end{array}$ & $\begin{array}{c}\text { Pulsation } \\
\text { frequency } \\
|\mathrm{Hz}|\end{array}$ & Note \\
\hline \multirow{6}{*}{1373} & \multirow{6}{*}{1123} & 10 & \multirow{6}{*}{$\begin{array}{c}\text { The } \\
\text { specimens } \\
\text { after } \\
\text { pulsation } \\
\text { forming } \\
\text { were water } \\
\text { quenched }\end{array}$} \\
\hline & & 20 & \\
\hline & & 25 & \\
\hline & & 30 & \\
\hline & & 35 & \\
\hline & & 40 & \\
\hline
\end{tabular}

\section{EXPERIMENTAL RESULTS AND DISCUSSION}

The summary deformation achieved during the pulsatory forming of cylindrical specimens made of experimental steel as a function of the pulsation frequency is shown in Fig. 2. For comparison, the graph also shows the course for cold-deformed $\mathrm{Al}$-specimens.

The course of yield strength and tensile strength after deformation as a function of the summary deformation is shown in Fig. 3. The maximum values of both the strength characteristics were achieved at summary deformations by $25 \%$, which corresponds 
with pulsation frequency of $30 \mathrm{~Hz}$. The course of plastic characteristics $\left(A_{5}\right.$ and $\left.Z\right)$ as a function of the summary deformation is shown in Fig. 4. The maximum values of the both plastic properties were achieved at summary deformations by $20 \%$, which corresponds with pulsation frequencies from 20 to $25 \mathrm{~Hz}$ (Fig. 2).

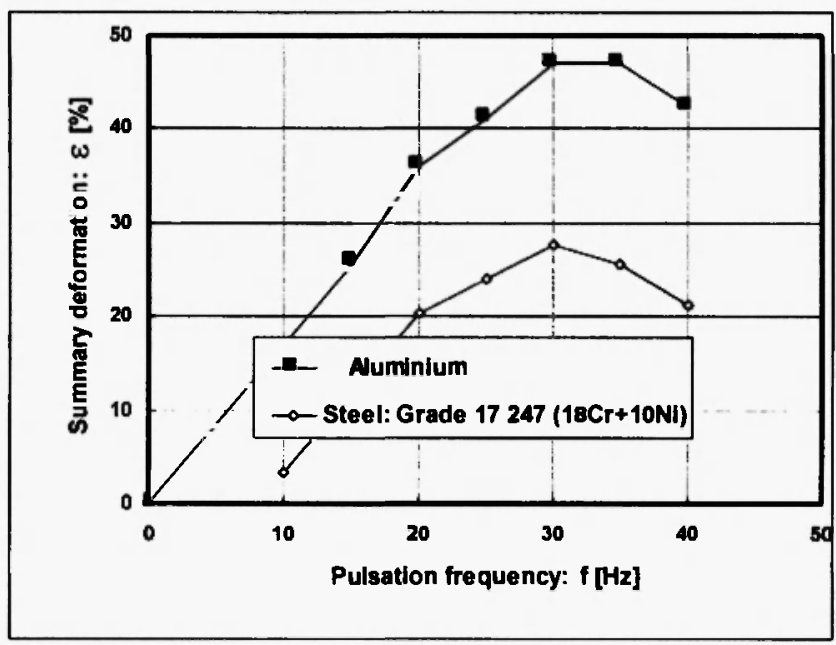

Fig. 2: Summary deformation as function of pulsation frequency (Al-cold forming, Steel$\mathrm{T}_{\text {finished }}=1123[\mathrm{~K}]$ )

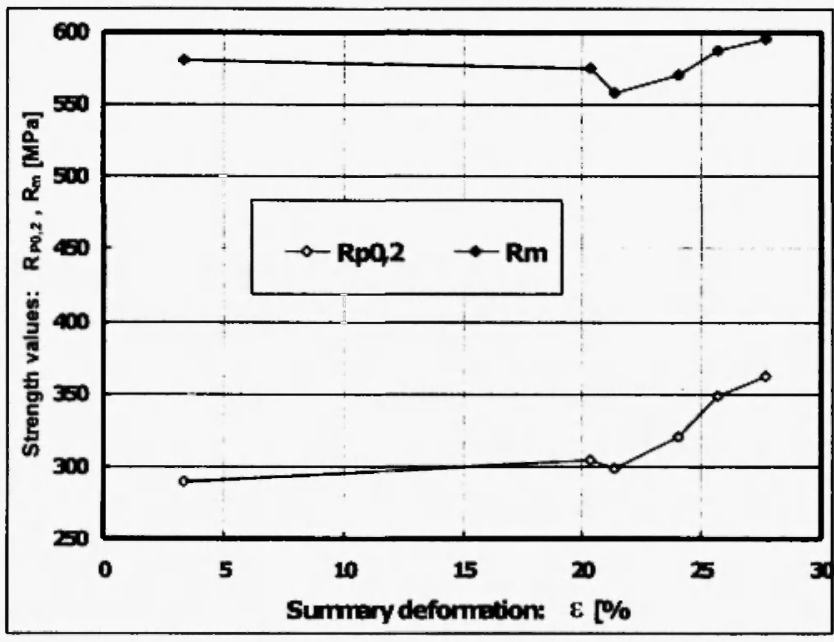

Fig.3: Strength values as function of summary deformation (Steel $-T_{\text {finished }}=1123[\mathrm{~K}]$ )

According to $/ 4 /$, where the calculated parameter " $\Theta$ ". as a function of the pulsation frequency is shown, that the parameter " $\Theta$ " grows with the growing frequency in the testing interval from 10 to $40 \mathrm{~Hz}$, which indicates a growth of deformation nonuniformity, which can mean a certain risk from the formability point of view. However, after exceeding the pulsation frequency of $20 \mathrm{~Hz}$ the growth of the barrel ratio significantly falls down. The course of strength characteristics as a function of parameter " $\Theta$ " is shown in Fig. 5, and the course of plastic properties is shown in Fig. 6. From the dependences between the mechanical characteristics and parameter " $\Theta$ ", and also according to $/ 4 /$, it is evident that significant changes of investigated properties after the "big barrel" area (area of non-uniformity deformation) were achieved. This result corresponds with the pulsation frequency value of $20 \mathrm{~Hz}$ (or more than $20 \mathrm{~Hz}$ ).

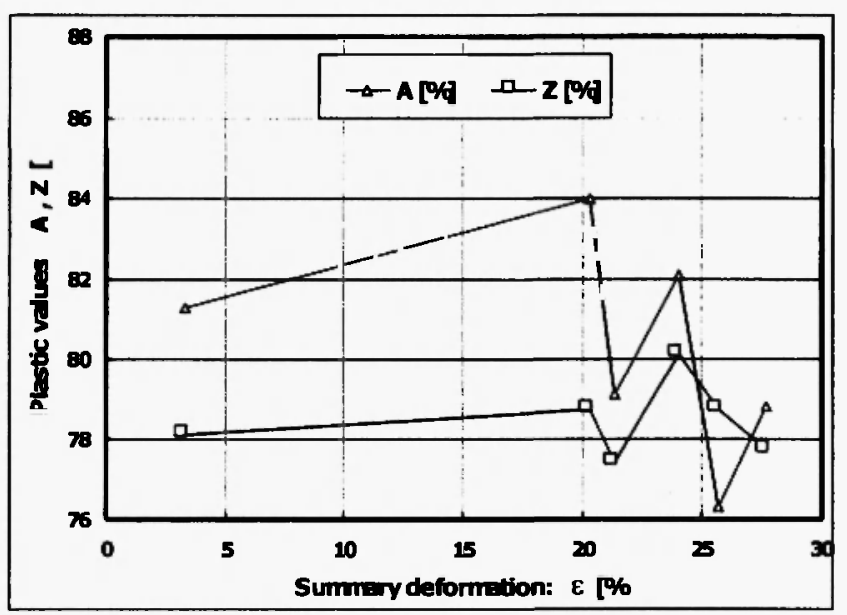

Fig.4: Plastic values as function of summary deformation (Steel - $T_{\text {finished }}=1123[\mathrm{~K}]$ )

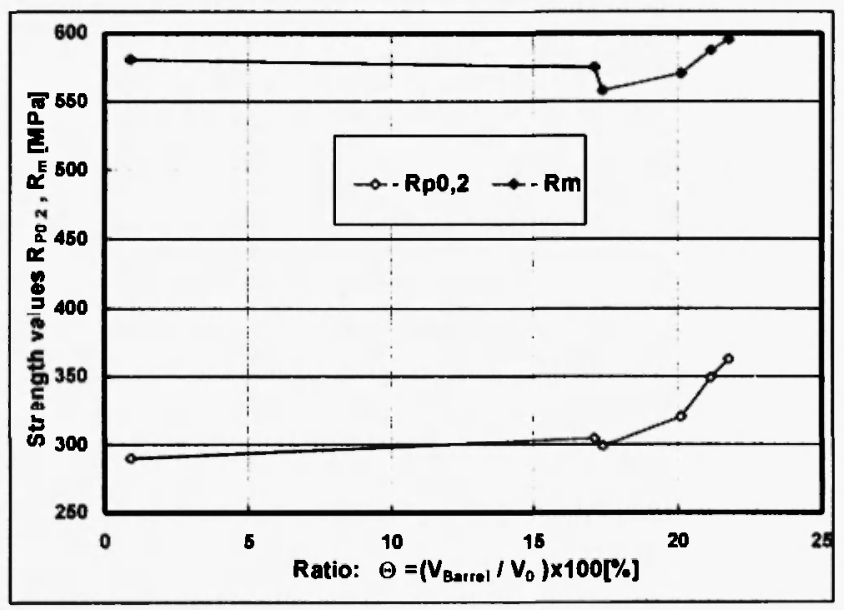

Fig. 5: Strength values as function of ratio $\Theta$ (Steel $\left.T_{\text {finished }}=1123[\mathrm{~K}], \mathrm{f}=10-40[\mathrm{~Hz}]\right)$ 


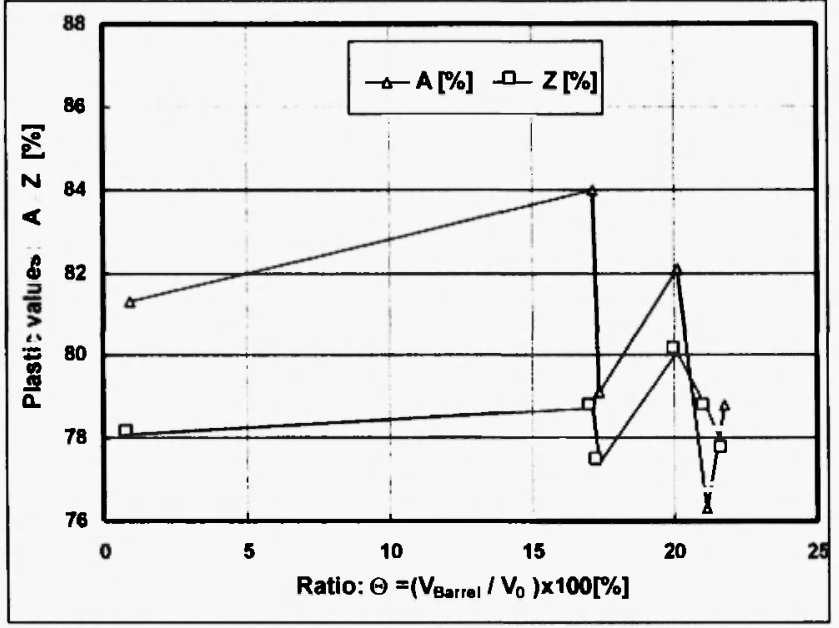

Fig. 6: Plastic values as function of ratio

$\Theta$ (Steel $\left.T_{\text {finished }}=1123[\mathrm{~K}], f=10-40[\mathrm{~Hz}]\right)$

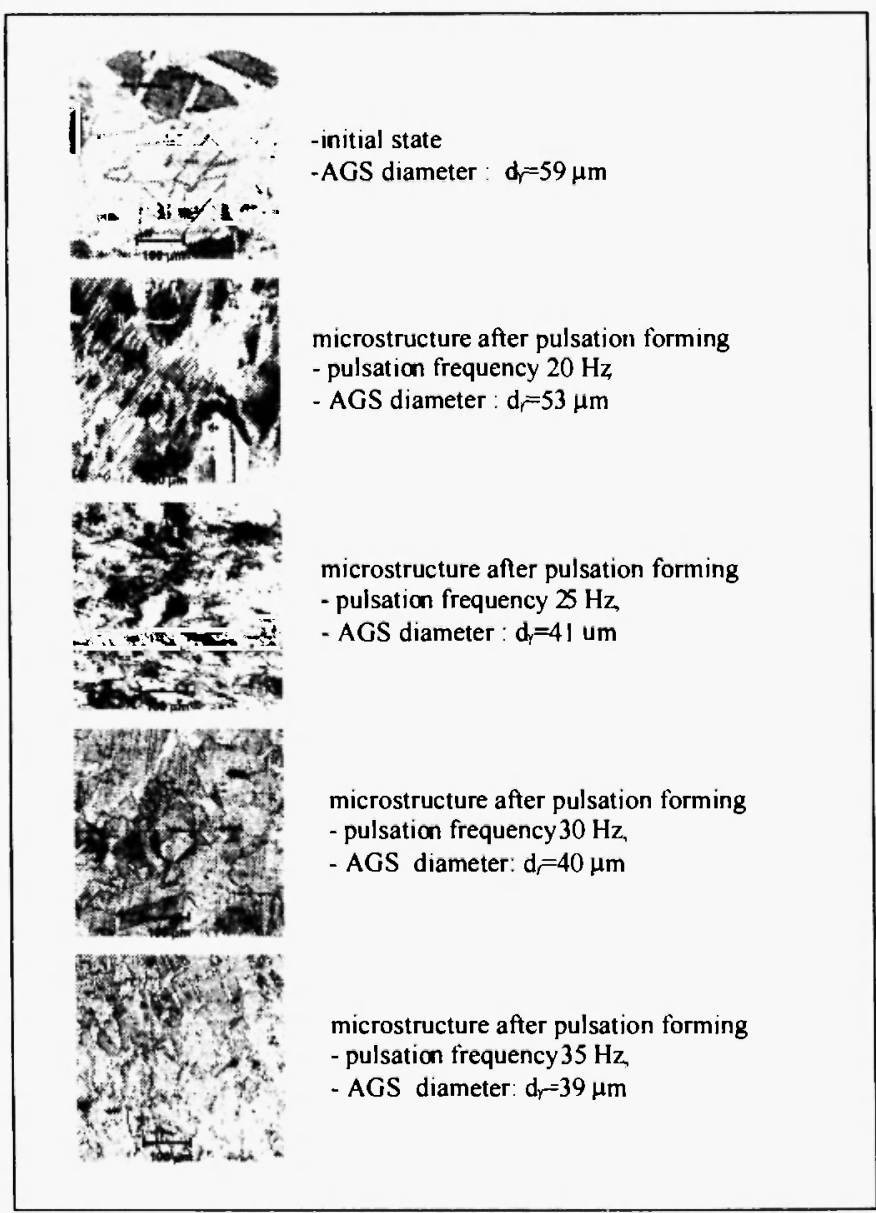

Fig. 7: Microstructures of initial state and after pulsation forming
The microstructures achieved after the pulsatory forming of the experimental material, as well as the initial state before forming, are documented in Fig. 7. They represent states at which the greatest grain refinement was achieved. With the increase of the pulsation frequency, the recrystallized grain share decreased and at the frequency of $25 \mathrm{~Hz}$ the structure mainly consisted of elongated grains. With a further increase of the pulsation frequency, the austenitic grains were restored again, with a more significant degree of heterogeneity.

\section{CONCLUSION}

1. After application of relative summary deformation of $25 \%$ at pulsation forming process, the following strength and plastic properties were achieved: $R_{p 0,2}=$ $350 \mathrm{MPa} ; R_{\mathrm{m}}=600 \mathrm{MPa} ; A_{5}=76 \% ; Z=78 \%$. As opposed to the classic conditions of forging these results represents a marked improvement of the level of plastic properties, in good agreement with the strength characteristics of steel grade $\mathrm{Cr} 18 \mathrm{Ni} 10$. The summary deformation of $25 \%$ corresponds with pulsation frequency of $30 \mathrm{~Hz}$.

2. The greatest values of strength characteristics of investigated steel corresponds with geometrical parameter $\Theta=20 \%$. At this value of geometrical parameters the level of the both investigated plastic properties ca $80 \%$ was achieved. The value of $\Theta=$ $20 \%$ plus represents better conditions of material flowing at pulsation forming process (decrease of deformation non-uniformity; lowering creation of barrel).

\section{ACKNOWLEDGEMENTS:}

The authors are grateful for support of experimental works by the international project "Stresscycling EUREKA E! 2336". 


\section{REFERENCES:}

I. T. Sakai and J.J. Jonas, Acta Metallurgica et Materialia, 32, 189-209 (1984).

2. F.J. Humph and M. Hatherly, Recrystallization and Related Annealing Phenomena, Pergamon Press, 1995.

3. K. Polák, Dynamic forming parameters, In: FORMING 99, Zlate Hory, Czech Republic, 1999; p. 64-71

4. T. Kvackaj, et al, Influence of pulsatory forming on mechanical properties of stainless steel, In: FORMING, Podlesice, Poland, 2003; p. 95-100 
